\title{
The Effect of Imagination and Visualization Education on Football Skills and Balance Abilities in Hearing Impaired Football Players
}

\author{
Mustafa Kaya, Nazmi Saritas \\ Erciyes University, Faculty of Sport Sciences, Kayseri, Turkey \\ Study Area: Kayseri, Turkey \\ Coordinates: $38^{\circ} 44^{\prime} \mathrm{N} ; 35^{\circ} 29^{\prime} \mathrm{E}$
}

Key words: Video training, Skill, Balance, Imagination training

\section{Abstract}

A study on 12 male volunteers who played football who did balance exercises and watched imagination and video training for $20 \mathrm{~min}$. After the exercises participated in the study as the experimental group. The control group consisted of 12 male volunteers, who played football, did balance exercises but did not practice imagination and video training. The test values having imagination and video training were compared with the control group. In the experimental group, there was a statistically significant difference in the static balance test, dynamic balance test and skill test. In the with within-group comparison of the control group, there was a statistically significant difference in the static balance test and skill test at the level of $\mathrm{p}<0.01$, and in the dynamic balance test. In conclusion, in this study comparing the effects of visualization and video training on the balance abilities and football skills in hearing-impaired individuals, When the two methods were compared, although both methods have a positive effect on the development of balance factors and football skills

position and speed of body parts, contact with objects, and the direction of gravity (Winter, 1995). Balance is important in sports to perform the movements. Balance can be defined as the adaptation of the body against gravity on the move and in the state of rest (Leavey et al., 2010).The ability to provide the balance of the body in a specific place or position is called static balance (Hazar \& Tasmektepligil, 2008). The dynamic balance is the result of neutralizing the external forces acting on the body by the muscles and soft tissues around the joints (Nichols et al., 1995).Imagination is the process of learning a new movement or perfecting an already known movement just by imagining in a planned way and intensely (by visualizing) without doing any actual exercises (Weinberg, 2008; Short et al., 2001). Imagination is a life in which real life is imitated. We can realize that we see what we imagine, feel the movements while imagining or experience the images of sounds, tastes, and odors even without real experiences (MacIntyre \& Moran, 2007). Imagination studies used by combining with technical, tactical, and motor studies ensure athletes improve in many fields (Aldemir et al., 2014). The fundamentals of teaching with video form are based on the principles of Bandura's Social Learning Theory. Teaching with video modeling is a method in which the target behavior is recorded by a video recorder to increase students' proprioceptive system consists of sensors sensitive to the 
capacities of keeping in mind, imitation skills and generalizing the skill to different conditions (Hitchcock et al., 2003). It is defined as making students watch the video recordings of the skill performed by a model and then allowing them to perform the skill (Bellini \& Akullian, 2007; Corbett, 2003). In other words, in teaching with video modeling, children are expected to sit at the television/computer and watch the video carefully, and, afterward, to display a performance related to the skill they watch. This process is repeated many times following the needs of the students.In this study, it is aimed to reveal the effects of the imagination and video education studies for hearing impaired individuals on their static and dynamic balance and football skills.

\section{Methodology:}

A total of 12 male volunteers between the ages of $18-22$, who played football, did balance exercises, and watched imagination and video training for $20 \mathrm{~min}$. after the exercises participated in the study as the experimental group. The control group consisted of 12 male volunteers who played football, did balance exercises but did not practice imagination and video education. A total of 24 hearing-impaired individuals participated in the study. All volunteers who participated in this study had a congenital hearing impairment and had hearing loss between (9o dB $110 \mathrm{~dB}$ ). The experimental group performed football activity, balance exercises, and imagination and video education 3 days a week for 8 weeks. The control group performed only 30 minutes of football activity and balance exercises 3 days a week for 8 weeks. Pre-test and post-test values of the participants were obtained, and the test values of the hearing impaired individuals having imagination and video education and the values of those who did not have imagination and video education were compared. The heights of the athletes were measured by the height measurement scale ( $0.1 \mathrm{~cm}$ accuracy), with bare feet or socks, and the body weights were measured with a scale (o.1 $\mathrm{kg}$ accuracy) while the athletes were wearing shorts. Body mass indexes were determined by dividing the body weights by the square of the heights (Zorba \& Ziyagil, 1995).

In the study, a biodex balance system (Biodex, Inc, Shirley, New York) was used for balance measurement. Biodex balance system uses a round platform that can be moved at the anterior-posterior and medial-lateral axis synchronously. It gives three result values as overall stability index, anterior-posterior stability index, and medial-lateral stability index (Cachupe et al., 2001). Among the obtained balance indices, the overall balance index is accepted as the best indicator for overall ability (OA). The subjects stood on both feet while their eyes are open and with a gap in the shoulder width between the feet, and the static balance and the 4th level dynamic balance tests were used. Tests were performed in a straight position with two feet.

Balance tests were performed as 1 repetition for $1 \mathrm{~min}$.
Before the tests, each volunteer performed a trial for $10 \mathrm{sec}$ to accommodate the static and dynamic balance tests and to get to know them. The participants were asked not to move and speak during the test. The tests of the participants losing their balance were started over again.

The goalpost was divided into 15 parts, and each part was scored. The volunteers shooted to the goalpost six times from $16,5 \mathrm{~m}$ away in the way they like, and the total of these shots were recorded (İri et al., 2009).

\begin{tabular}{|l|l|l|l|l|}
\hline 4 point & 2 point & & 2 point & 4 point \\
\hline 3 point & 1 point & & 1 point & 3 point \\
\hline 4 point & 2 point & & 2 point & 4 point \\
\hline
\end{tabular}

The Process of Teaching with Video modelling

These tools can be used easily for several purposes in individuals with developmental insufficiency. Thus, when different costs and the ease of handling are taken into consideration, mobile electronic devices such as tablets and mobile phones can also be used as well as television and computer in the process of preparing and watching video records. In this study, mobile phones have been used for the process of teaching with video modeling. The manners of application of static balance, dynamic balance, and football skill tests were performed and recorded by the authors, and shared with the volunteers. After the target skill that the participant would learn was determined, the volunteers were asked to record and watch the way of practicing the football skill and the practice manner of the static and dynamic balance tests via their mobile phones. The imagination study was carried out 3 days a week for 20 minutes, without performing any actual exercise, only dreaming in a planned way and intensely by visualizing. The analysis of the data was performed by IBM SPSS 20.o. The normality of the distribution was made by the Shapiro-Wilk test. Distributions were found to be normal. The data were shown by arithmetic median and standard deviation. In the comparison of the independent groups, the independent sample t-test was used, and in the comparison of the dependent groups, a paired sample t-test was used. The significance level was taken as $\mathrm{p}<0.05$.

\section{Results:}

Table-1: The physical characteristics of the experimental groups $(n=12)$ and the control group $(n=12)$

\begin{tabular}{llllll}
\hline Variable & \multicolumn{4}{l}{ Experimental Group } & \multicolumn{2}{l}{ Control Group } \\
& Test & $\mathrm{X} \pm \mathrm{SD}$ & $\mathrm{X} \pm \mathrm{SD}$ & $\mathrm{t}$ & $\mathrm{p}$ \\
\hline Age(Year) & Pre-test & $20.08 \pm 1.24$ & $20.17 \pm 1.47$ & 0.150 & 0.882 \\
& Post-test & $20.08 \pm 1.24$ & $20.17 \pm 1.47$ & 0.150 & 0.880 \\
Height & Pre-test & $173.25 \pm 4.83$ & $172.42 \pm 3.73$ & -0.473 & 0.641 \\
$(\mathrm{~cm})$ & Post-test & $173.25 \pm 4.83$ & $172.42 \pm 3.73$ & -0.473 & 0.641 \\
Body wei- Pre test & $66.58 \pm 2.47$ & $66.50 \pm 2.54$ & -0.082 & 0.936 \\
ght (kg) & Post test & $66.75 \pm 1.82$ & $66.33 \pm 2.15$ & -0.513 & 0.613 \\
& p & 0.551 & 0.586 & &
\end{tabular}


Table-1: The comparison of the static balance, dynamic balance and skill test values of the experimental groups \& the control group

\begin{tabular}{llllll}
\hline Variable & \multicolumn{4}{l}{ Experimental Group } & \multicolumn{2}{l}{ Control Group } \\
& Test & $\mathrm{X} \pm \mathrm{SD}$ & $\mathrm{X} \pm \mathrm{SD}$ & $\mathrm{t}$ & $\mathrm{p}$ \\
\hline Static & Pre test & $0.79 \pm 0.17$ & $0.77 \pm 0.16$ & -0.372 & 0713 \\
Balance & Post test & $.667 \pm 0.11$ & $0.60 \pm 0.13$ & -1.383 & 0.181 \\
& $\mathrm{p}$ & $0.004^{* *}$ & $0.003^{* *}$ & & \\
Dynamic & Pre test & $1.78 \pm 0.24$ & $1.73 \pm 0.21$ & -0.451 & 0.657 \\
Balance & Post test & $1.367 \pm 0.20$ & $1.35 \pm 0.21$ & -0.202 & 0.842 \\
& $\mathrm{p}$ & $0.000^{* * *}$ & $0.000^{* * *}$ & & \\
Skill & Pre test & $14.42 \pm 0.79$ & $13.50 \pm 1.62$ & -1.757 & 0.093 \\
& Post test & $15.83 \pm 0.83$ & $15.83 \pm 0.83$ & 0.000 & 1.000 \\
& $\mathrm{p}$ & $0.001^{* * *}$ & $0.003^{* *}$ & & \\
\hline
\end{tabular}

No statistically significant difference was found in the pre-test and post-test values of the static balance test, dynamic balance test and skill test of experimental and control groups. In the with within-group comparison of the experimental group, a statistically significant difference occurred in static balance test, dynamic balance test and skill test. Again, in the with within-group comparison of the control group, a statistically significant difference was observed in the static balance test, skill test and dynamic balance test.

\section{Discussion \& Conclusion:}

In this study, it was aimed to compare the effects of two different methods as performing and not performing imagination and video education in hearing-impaired individuals on balance functions and football skills.

Mental education is an education that is used in sports skills studies. Skills can be developed by positive imagination and these skills can be displayed more successfully and strongly by fixing their weaknesses. The mental workout is a psychological skill, and it has an important power to increase the performance of the athlete (Konter, 1999).

No significant difference was detected in the intergroup comparison between the static balance test, dynamic balance test, and football skill values of the hearing impaired individuals having imagination and video education and those who did not have the education in question. On the other hand, in the within-group comparisons, a significant difference occurred in the static balance, dynamic balance, and skill tests in both groups. Mental training is a psychological skill and has an important power to improve the performance of the athlete (Konter, 1999). Furthermore, it is known that mental training and cognitive-based teaching methods, which are among the learning-accelerating practices, increase the learning of the athletes' skills (Mahoney \& Sunin, 1986). Sosovec (2004) examined the effects of visual imagination on the penalty shootout in football and divided the subjects into mental, physical, and mental and physical training groups. It was determined that, for both of the physical and mental training groups, the rates of the shots on target was higher than the other two groups. In another study, video-assisted mental training has been shown to have a positive effect on shooting skills in football. According to the findings of the research, mental training practice combined with physical training is more effective than only physical or mental training practice (Özdal et al., 2013). Similarly, in a study conducted on the effect of the exercise activities on hearingimpaired children, it is stated that exercises affect visual motoric characteristics and they are efficient in overcoming the deficiencies related to the vestibular system (Rajendran et al., 2013). However, it is believed that the fact that no difference occurred in the comparison of the experimental and control groups in the study arouse from that both groups included individuals doing sports and the tests were learned. There are studies revealing that static and dynamic balance skills of hearing-impaired children are affected depending on the age, sex, etiology, and level of the hearing loss. Especially the negative effects of heavy hearing losses on balance and postural quality have been proved (Juntunen et al., 1987). According to another study, it was observed that children having cochlear implantation and bilateral partial hearing loss at $60 \mathrm{~dB}$ and above had balance problems (Livingstone \& McPhilips, 2011).In the study, although the volunteers in the experimental and control groups had severe hearing impairment, within-group static and dynamic balance values were significant in both groups. This is thought to be due to the fact that these individuals play sports and that the sport positively affects balance values in hearing-impaired individuals. The effect of a 16-week rhythmic gymnastics program on dynamic balance in 29 hearing-impaired children were examined. Children were divided into two groups as the experimental group and the control group. As a result of the study, it was found that rhythmic gymnastics exercises improved balance in hearing-impaired children (Fotiadou, 2002). These results support our study with the effect of physical activity. It was found that children having late hearing loss were more successful to provide balance than those having congenital hearing loss (Selz et al., 1996). In this study, the volunteers in the experimental and control groups had a congenital hearing impairment. Thus, this is thought to be the reason for the significant differences in within-group values. Although there were improvements in both groups with the effect of the sport on balance values, there were no differences between groups, and it is believed that this is because the volunteers were congenital hearing-impaired individuals. In further studies, congenital and late hearing impaired individuals or late hearing-impaired groups can be compared.In this study, a statistically significant difference occurred in the pre-test and post-test values of the shot to the goalpost test of the experimental and control groups. Similarly, it was determined that there was no significant difference between the pre and post-test averages of the variables such as dribble, pass, shot, and 
bounce in males between the ages of 10-13 (Kurban \& Kaya, 2017). In parallel with this information, in the study conducted on non-disabled individuals between the ages of 12-14, it was revealed that the values of slalom, shot to the goal, bounce on the head, and bounce with foot have a significant difference (İri et al., 2009).As can be seen, imagination, especially in sports, training, or precompetition, which requires a more complex and systematic presentation of motor skills, ensures that the motor skills are reinforced more positively. Sports rules for hearing-impaired athletes do not differ from those for normal athletes, and this study, conducted with hearingimpaired individuals, have similar results when compared with those conducted with non-disabled individuals. Therefore it is thought that hearing-impaired individuals should be directed to popular sports like football. The limitations of this study are as follows; the difficulties in communication with hearing-impaired individuals, the difficulties in transportation to the laboratory in which measurements would be taken, deficiencies in the balance levels of the individuals due to their severe hearing impairment, their getting used to the balancing equipment and the problems in terms of taking the objective measurement.

\section{References:}

Aldemir, Y.G., Biçer, T. \& Kale, E.K. (2014): The effects of imagery exercises on problem solving in football players. J. Sports Perform. Res., 5(2):37-45.

Bellini, S. \& Akullian, J.A. (2007): Meta-analysis of video modeling and video self-modeling interventions for children and adolescents with autism spectrum disorders. Except. Children, 73:264-287.

Cachupe, W.J., Shifflett, B., Kahanov, L. \&Wughalter, E.H. (2001): Reliability of biodex balance system measures. Measure. Phy. Edu. Execer. Sci., 5(2):97-108.

Corbett, B.A. (2003): Video modeling: A window into the world of autism. Behav. Anal. Today., 4:367-377.

Fotiadou, E., Giagazoglou, P., Kokaridas, D., Angelopoulou, N., Tsimaras, V. \& Tsorbatzoudis, C. (2002): Effect of rhythmic gymnastics on the dynamic balance of children with deafness. Eu.J. Spe. Need Edu., 17(3):301-309.

Hazar, F. \& Taşmektepligil, M.Y. (2008): Investigation of the effects of balance and flexibility on agility in the prepubertal period. Sportmeter J. Phy. Edu. Sport Sci., 15(1):9-12.

Hitchcock, C.H., Dowrick, P.W. \& Prater, M.A. (2003): Video selfmodeling in school based settings. Remed. Spec. Edu., 56:3645 .

İri, R., Sevinç, H. \& Süel, E. (2009): The effect of football skill training applied to children aged $12-14$ on basic motoric properties. L. Hum.Sci., 6(2):1303-5134.

Juntunen, J., Matikainen, E., Ylikoski, J., Ylikoski, M., Vaheri, E. \& Ojala, M. (1987): Postural body sway and exposure to highenergy impulse noise. Lancet, 2 (8553):261-264.
Konter, E. (1999): Mental Training in Applied Sports Psychology, 1st Edition. Pub by:Ankara: Nobel publications.

Kurban, M. \& Kaya, Y. (2017): Investigation of the effect of football basic technical training on some motoric and technical skills development of 10-13 age group children, J. Sports Perf. Res., 8(3):210-221.

Leavey, V., Sandrey, M.A. \& Dahmer, G. (2010): The comparative effects of a six-week balance, gluteus medius strength, and combined programs on dynamic postural control. L. Sport Rehabil., 19(3):268-87.

Livingstone, N. \& McPhillips, M. (2011): Motor skill deficits in children with partial hearing. Develop. Med. Child Neurol., $53: 836-42$

MacIntyre, T.E. \& Moran, A.P. (2007): A qualitative investigation of metaimagery processes and imagery direction among athletes. J. Imag. Res. Sport Phys. Activ., 2(1):1-20.

Mahoney, M. \& Suinn, R.M. (1986): History and Overview of Modern Sport Psychology. Clini. Psychol., 39(3):64-68.

Nichols, D.S., Glenn, T.M. \& Hutchinson, K.J. (1995): Change in the mean center of balance during balance testing in young adults. Phys. Ther., 75(8):699-706.

Özdal, M., Akcan, F. \& Abakay, U. (2013): The influence of video assisted mental training program on future-shooting ability. J. Sports Perf. Res., 4(2):40-46

Özkatar-Kaya, E. \& Șanal, M. (2011): The investigation of stress and aggression levels in hearing impaired sportsmen aged between 18-25 years old. Ovidius Univers. Ann., Ser. Phy. Edu. Sport Sci., Move. Health, 11(2):166-171.

Rajendran, V. \& Roy, F.G. (2013): Jeevanantham D. Effect of exercise intervention on vestibular related impairments in hearing-impaired children. Alexandria J. Med., 49(1):7-12.

Selz, P.A., Girardi, M., Konrad, H.R. \& Hughes, L.F. (1996): Vestibular deficits in deaf children. Otolaryngol. Head Neck Surg., 115(1):70-7.

Sosovec, L.G. (2004): Internal Visual Imagery and ITS Effect on Penalty Kicks in Soccer. Master Thesis, South Dakota State University.

Short, S.E., Afremow, J. \& Overby, L. (2001): Using mental imagery to enhance children's motor performance. JOPERD, 72(2):1923.

Yıldız, K., Pepe, O., Sarıtaş, N. \& Özkatar Kaya, E. (2012): An investigation over the levels of social anxiety according to the gender factors of hearing-impaired adolescent athletes between the ages of 12-16. Niğde Univers. J. Phy. Edu. Sport Sci., 6(1):56-61.

Zorba, E. \& Ziyagil, M.A. (1995): Body composition and measurement methods. Gen. Pub. Trabzon, 184:252-293.

Weinberg, R. (2008): Does imagery work? Effects on performance and mental skills. J. Imag. Res. Sport Phys. Activ., 3(1):1-21.

Winter, D.A. (1995): Human balance and postural control during standing and walking. Gait. Post., 3:19. 